\title{
Case Reports Showing a Long-Term Effect of Subanesthetic Ketamine Infusion in Reducing L-DOPA-Induced Dyskinesias
}

\author{
Scott J. Sherman ${ }^{\mathrm{a}} \quad$ Miguel Estevez $^{\mathrm{b}} \quad$ Ari B. Magill ${ }^{\mathrm{a}}$ Torsten Falk $^{\mathrm{a}}$ \\ ${ }^{a}$ Department of Neurology, University of Arizona, Tucson, Ariz., and ${ }^{b}$ Neurometrica, LLC, \\ Eugene, Oreg., USA
}

\section{Key Words}

Parkinson's disease · Depression · Pain · Hypersynchrony · NMDA receptors · Levodopa

\begin{abstract}
Ketamine is an FDA-approved drug with a known safety profile. Low-dose subanesthetic intravenous ketamine infusion treatment has led to long-term reduction of treatmentresistant depression and of chronic pain states. We report on low-dose subanesthetic intravenous ketamine infusion treatment in Parkinson's disease (PD) patients by 5 case studies and show a long-lasting therapeutic benefit to reduce L-DOPA-induced dyskinesia (LID), improve on time, and reduce depression. Based on the literature we hypothesize that low-dose ketamine may act as a 'chemical deep brain stimulation', by desynchronizing hypersynchronous oscillatory brain activity, including in the basal ganglia and the motor cortex. The presented PD case reports indicate tolerability, safety and long-term beneficial effects of lowdose ketamine infusion that should be further investigated in a properly controlled prospective clinical trial for treatment of LID, as well as the prevalent nonmotor features pain and depression in PD patients.

\section{Introduction}

Low-dose subanesthetic ketamine is used to treat various chronic pain syndromes, especially those with a neuropathic component, and a single intravenous infusion has been shown to lead to long-term analgesic effects lasting several months [1]. Recent clinical trials

\section{KARGER}

Scott J. Sherman

Department of Neurology, University of Arizona

1501 North Campbell Avenue, P.O. Box 245023

Tucson, AZ 85724-5023 (USA)

E-Mail ssherman@u.arizona.edu 
Sherman et al.: Case Reports Showing a Long-Term Effect of Subanesthetic Ketamine Infusion in Reducing L-DOPA-Induced Dyskinesias

also showed that low-dose ketamine infusion paradigms are safe, effective, and well tolerated for treatment-resistant depression [2-4] and posttraumatic stress disorder (PTSD) [5]. Our present case studies suggest that symptoms of Parkinson's disease (PD) may also be ameliorated by low-dose ketamine and provide the rationale for further testing in clinical trials. Hypotheses of the pathophysiology of L-DOPA-induced dyskinesia (LID) and motor fluctuations in PD include hypersynchrony of electric activity [6], a commonality between LID, depression and PTSD. LID and PD are associated with reduced dopaminergic innervation to the striatum and a pronounced increase in $\theta-(4-10 \mathrm{~Hz})$ and $\beta$-band $(13-30 \mathrm{~Hz})$ oscillations in the basal ganglia [7]. And treatments like deep brain stimulation (DBS) that disrupt, or lesions to the subthalamic nucleus (STN) and pallidotomy, that eliminate the putative sources of these hypersynchronous oscillations improve motor symptoms [8]. Based on this information, we hypothesize that use of low-dose ketamine infusions might help with treatment of PD, especially LID.

\section{Case Presentation}

We report on 5 cases of subanesthetic ketamine infusion in patients with PD (Hoehn and Yahr: 2.5-3) identified by a retrospective chart review. The case review was approved by the Institutional Review Board, University of Arizona, and written informed consent was received from the participants. Ketamine was indicated for a variety of comorbid conditions. The level of documentation of PD and LID symptoms pre- and post-infusion was variable, but in most cases included standardized clinical rating scales collected by movement disorder specialists. Patient details are summarized in table 1. Overall, the case reports indicate excellent tolerability and safety of ketamine in this group of patients. Patients were treated in the intensive care unit using a protocol developed by one of the authors (M.E.) for treatment of intractable pain that specified titration of ketamine to a target rate of $0.15-0.3$ $\mathrm{mg} / \mathrm{kg} / \mathrm{h}$ for $50-96$-hour periods. There was no significant sedation in any of the cases (evaluated with the Richmond Agitation Sedation Scale: 0.2-0.42).

Case No. 1, a 64-year-old male with long-standing PD of 20 years duration, demonstrated remarkable resolution of LID as determined by review of all-day diaries of his motor fluctuations, and clinical observation (fig. 1a-d). This patient was treated for intractable back pain due to severe lumbar degenerative disk disease which was exacerbated by frequently severe dyskinesia. During admission, no adjustments were made to the dosages of dopamine replacement medications (L-DOPA-equivalent dose: $2,400 \mathrm{mg} /$ day) or other medications, yet his dyskinesia improved markedly during and after the infusion. The patient continues to be followed by one of the investigators (S.J.S.) and has remained free of dyskinesia.

Similarly, in case No. 2, a 62-year-old male (L-DOPA equivalent: 2,150 mg; disease duration: $>10$ years) received a ketamine infusion to treat pain exacerbated by dyskinesia. Amantadine (200 mg daily) treatment had failed to improve his LID. There was a dramatic reduction in dyskinesia during the ketamine infusion and for at least 3 weeks post-infusion, as reported by one of the authors (M.E.), though less quantitative data is available from chart review.

Case No. 3, an 84-year-old male (L-DOPA equivalent: 1,971 mg; disease duration: 12 years), was treated for severe back pain and depression. The patient had significant comorbid medical problems including reduced cardiac ejection fraction and arrhythmia. Ketamine dramatically improved the patient's depression, pain, and acutely improved his motor symptoms. Though dyskinesia was mild, it is notable that it completely subsided following the infusion, and that there was acute improvement in the Unified Parkinson's Disease Rating 
Sherman et al.: Case Reports Showing a Long-Term Effect of Subanesthetic Ketamine Infusion in Reducing L-DOPA-Induced Dyskinesias

Scale (UPDRS) part III exam (before infusion: 40.5; during: 28). His depression was dramatically improved (patient was suicidal before infusion and only mildly depressed on subsequent follow-up visits, followed by S.J.S.). This case supports the safety and feasibility of using low-dose ketamine even in patients of advanced age and with comorbid conditions.

Cases No. 4 and 5 are female PD patients, 46 and 54 years old with relatively early-onset PD (L-DOPA equivalent: $800 \mathrm{mg}$; disease duration: 6 and 8 years), who were treated for intractable headaches. Both had received STN DBS which had previously resolved their dyskinesia and motor fluctuations. In case No. 4, the intensity of DBS stimulation was reduced by 0.3 volts bilaterally without loss of motor benefit and improvement in the DBS-induced side effect of dysarthria. These cases are included for completeness of documentation and safety data, though there was less dramatic effect on motor symptoms, perhaps due to ongoing DBS treatment.

\section{Discussion}

Overall, the case reports suggest that low-dose ketamine infusions are well tolerated in patients with PD and can improve pain and depression in this setting, supporting reports in other patient populations $[1-5,9]$. This is important since depression is a critical problem for many PD patients [10] and depression is possibly worsened by L-DOPA [11]. We also noted an acute improvement in tremor as has been reported in a single previous case [12]. Most remarkably, we have observed a prominent and prolonged post-infusion improvement in LID.

The therapeutic effects seen could be due to low-dose ketamine acting as a 'chemical DBS' by desynchronizing neural hypersynchronous oscillatory activity involved in LID sufficiently to induce a lasting antidyskinetic effect. This hypothesis is based on recent work showing that subanesthetic ketamine leads to decreased $\beta(13-30 \mathrm{~Hz})$ and increased $\gamma(>50$ $\mathrm{Hz}$ ) oscillations in cortical areas in healthy human subjects [13], and preclinical data in rodents where low-dose ketamine treatment induced coherent oscillations in low $\gamma(50 \mathrm{~Hz})$, high $\gamma(80 \mathrm{~Hz})$ and high frequency $(150 \mathrm{~Hz})$ bands, with different behavior in four structures studied: motor cortex, caudate-putamen, substantia nigra pars reticulata and STN [14]. And a recent study reported that STN DBS appears to disentangle the abnormal relationship between the slow beta and fast $\gamma$ oscillations in the motor cortex in PD patients [15].

Ketamine is an FDA-approved drug with a known safety profile. It is possible that its use in a special population, e.g. PD patients, could result in unexpected treatment-emergent adverse events; however, our preliminary case series supports safety in this population. Since these are case reports and not cases within a controlled clinical trial, neither placebo effects or learning effects on patient-derived ratings can be ruled out as contributing factors to the reported long-term antidyskinetic activity.

In conclusion the presented PD case reports indicating long-term effects of low-dose subanesthetic ketamine infusion should be further investigated in a properly controlled prospective clinical trial for treatment of LID, and may also be considered for study of pain and depression in PD which are prevalent nonmotor features.

\section{Statement of Ethics}

The authors have no ethical conflicts to disclose. 
Sherman et al.: Case Reports Showing a Long-Term Effect of Subanesthetic Ketamine Infusion in Reducing L-DOPA-Induced Dyskinesias

\section{Disclosure Statement}

None of the authors have conflicts of interest to disclose.

\section{References}

1 Niesters M, Martini C, Dahan A: Ketamine for chronic pain: risks and benefits. Br J Clin Pharmacol 2014;77:357-367.

$\checkmark 2$ Diamond PR, Farmery AD, Atkinson S, Haldar J, Williams N, Cowen PJ, et al: Ketamine infusions for treatment resistant depression: a series of 28 patients treated weekly or twice weekly in an ECT clinic. J Psychopharmacol 2014;28:536-544.

-3 Murrough JW, Perez AM, Pillemer S, Stern J, Parides MK, Aan Het Rot M, et al: Rapid and longer-term antidepressant effects of repeated ketamine infusions in treatment-resistant major depression. Biol Psychiatry 2013;74:250-256.

4 Murrough JW, Iosifescu DV, Chang LC, Al Jurdi RK, Green CE, Perez AM, et al: Antidepressant efficacy of ketamine in treatment-resistant major depression: a two-site randomized controlled trial. Am J Psychiatry 2013;170:1134-1142.

-5 Feder A, Parides MK, Murrough JW, Perez AM, Morgan JE, Saxena S, et al: Efficacy of intravenous ketamine for treatment of chronic posttraumatic stress disorder: a randomized clinical trial. JAMA Psychiatry 2014;71:681-688.

$\checkmark 6$ Olanow CW, Stern MB, Sethi K: The scientific and clinical basis for the treatment of Parkinson disease. Neurology 2009;72:S1-S136.

7 Jenkinson N, Brown P: New insights into the relationship between dopamine, beta oscillations and motor function. Trends Neurosci 2011;34:611-618.

$>8$ Benabid AL, Chabardes S, Mitrofanis J, Pollak P: Deep brain stimulation of the subthalamic nucleus for the treatment of Parkinson's disease. Lancet Neurol 2009;8:67-81.

$\checkmark 9$ Lapidus KAB, Levitch CF, Perez AM, Brallier JW, Parides MK, Soleimani L, et al: A randomized controlled trial of intranasal ketamine in major depressive disorder. Biol Psychiatry 2014;76:970-976.

10 Marsh L: Depression and Parkinson's disease: current knowledge. Curr Neurol Neurosci Rep 2013;13:409.

11 Eskow Jaunarajs KL, Angoa-Perez M, Kuhn DM, Bishop C: Potential mechanisms underlying anxiety and depression in Parkinson's disease: consequences of L- DOPA treatment. Neurosci Biobehav Rev 2011;35:556-564.

12 Wright JJ, Goodnight PD, Mcevoy MD: The utility of ketamine for the preoperative management of a patient with Parkinson's disease. Anesth Analg 2009;108:980-982.

13 Muthukumaraswamy SD, Shaw AD, Jackson LE, Hall JE, Moran R, Saxena N: Evidence that subanesthetic doses of ketamine cause sustained disruptions of NMDA and AMPA-mediated frontoparietal connectivity in humans. J Neurosci 2015;35:11694-11706.

14 Nicolás MJ, López-Azcárate J, Valencia M, Alegre M, Pérez-Alcázar M, Iriarte J, et al: Ketamine-induced oscillations in the motor circuit of the rat basal ganglia. PLoS One 2011;6:e21814.

15 De Hemptinne C, Swann NC, Ostrem JL, Ryapolova-Webb ES, San Luciano M, Galifianakis NB, et al: Therapeutic deep brain stimulation reduces cortical phase-amplitude coupling in Parkinson's disease. Nat Neurosci 2015;18:779-786. 


\section{Case Reports in Neurology}

Sherman et al.: Case Reports Showing a Long-Term Effect of Subanesthetic Ketamine Infusion in Reducing L-DOPA-Induced Dyskinesias

Table 1. Patient details

\begin{tabular}{|c|c|c|c|c|c|c|c|c|c|c|c|c|c|c|c|c|}
\hline \multirow{3}{*}{$\begin{array}{l}\text { Case } \\
\text { No. }\end{array}$} & \multicolumn{4}{|c|}{ Demographics } & \multirow{3}{*}{$\begin{array}{l}\text { L-DOPA } \\
\text { equiv. }\end{array}$} & \multicolumn{5}{|c|}{ Ketamine infusion } & \multicolumn{6}{|c|}{ Clinical effects of ketamine } \\
\hline & \multirow[t]{2}{*}{ age } & \multirow[t]{2}{*}{$\operatorname{sex}$} & \multirow[t]{2}{*}{$\begin{array}{l}\text { disease } \\
\text { duration }\end{array}$} & \multirow{2}{*}{$\begin{array}{l}\text { Hoehn } \\
\text { and } \\
\text { Yahr }\end{array}$} & & \multirow[t]{2}{*}{ indication } & \multirow{2}{*}{$\begin{array}{l}\text { start- } \\
\text { ing } \\
\text { dose }\end{array}$} & \multirow[t]{2}{*}{$\begin{array}{l}\max . \\
\text { dose }\end{array}$} & \multirow{2}{*}{$\begin{array}{l}\text { dura- } \\
\text { tion, } \\
\mathrm{h}\end{array}$} & \multirow{2}{*}{$\begin{array}{l}\text { aver- } \\
\text { age } \\
\text { dose }\end{array}$} & \multicolumn{2}{|c|}{$\begin{array}{l}\text { Effect on } \\
\text { dyskinesia }\end{array}$} & \multicolumn{3}{|l|}{ Pain } & \multirow{2}{*}{$\begin{array}{l}\text { side } \\
\text { effects } \\
\text { RASS }\end{array}$} \\
\hline & & & & & & & & & & & before & after & before & during & $\overline{\text { after }}$ & \\
\hline 1 & 64 & $\mathrm{~m}$ & 20 & 3 & 2,400 & back pain & 0.05 & 0.3 & 50 & n.d. & +++ & + & n.d. & n.d. & n.d. & n.d. \\
\hline 2 & 62 & $\mathrm{~m}$ & $>10$ & 3 & 2,150 & $\begin{array}{l}\text { painful } \\
\text { dyskinesia }\end{array}$ & 0.15 & 0.15 & 72 & 0.15 & +++ & + & n.d. & n.d. & n.d. & n.d. \\
\hline 3 & 84 & $\mathrm{~m}$ & 12 & 3 & 1,971 & back pain & 0.05 & 0.15 & 65 & 0.09 & + & none & 5 & 0.73 & 0 & 0.14 \\
\hline 4 & 46 & $\mathrm{f}$ & 6 & 2.5 & 400 & headache & 0.05 & 0.15 & 96 & 0.09 & none & none & 10 & 5.5 & 5 & 0.42 \\
\hline 5 & 54 & $\mathrm{f}$ & 8 & 2.5 & 400 & headache & 0.05 & 0.15 & 72 & 0.12 & none & none & n.d. & n.d. & n.d. & n.d. \\
\hline
\end{tabular}

n.d. = Not determined; UPDRS = Unified Parkinson's Disease Rating Scale, 0-10 Pain Scale Assessment; RASS = Richmond Agitation Sedation Scale. 
Sherman et al.: Case Reports Showing a Long-Term Effect of Subanesthetic Ketamine Infusion in Reducing L-DOPA-Induced Dyskinesias
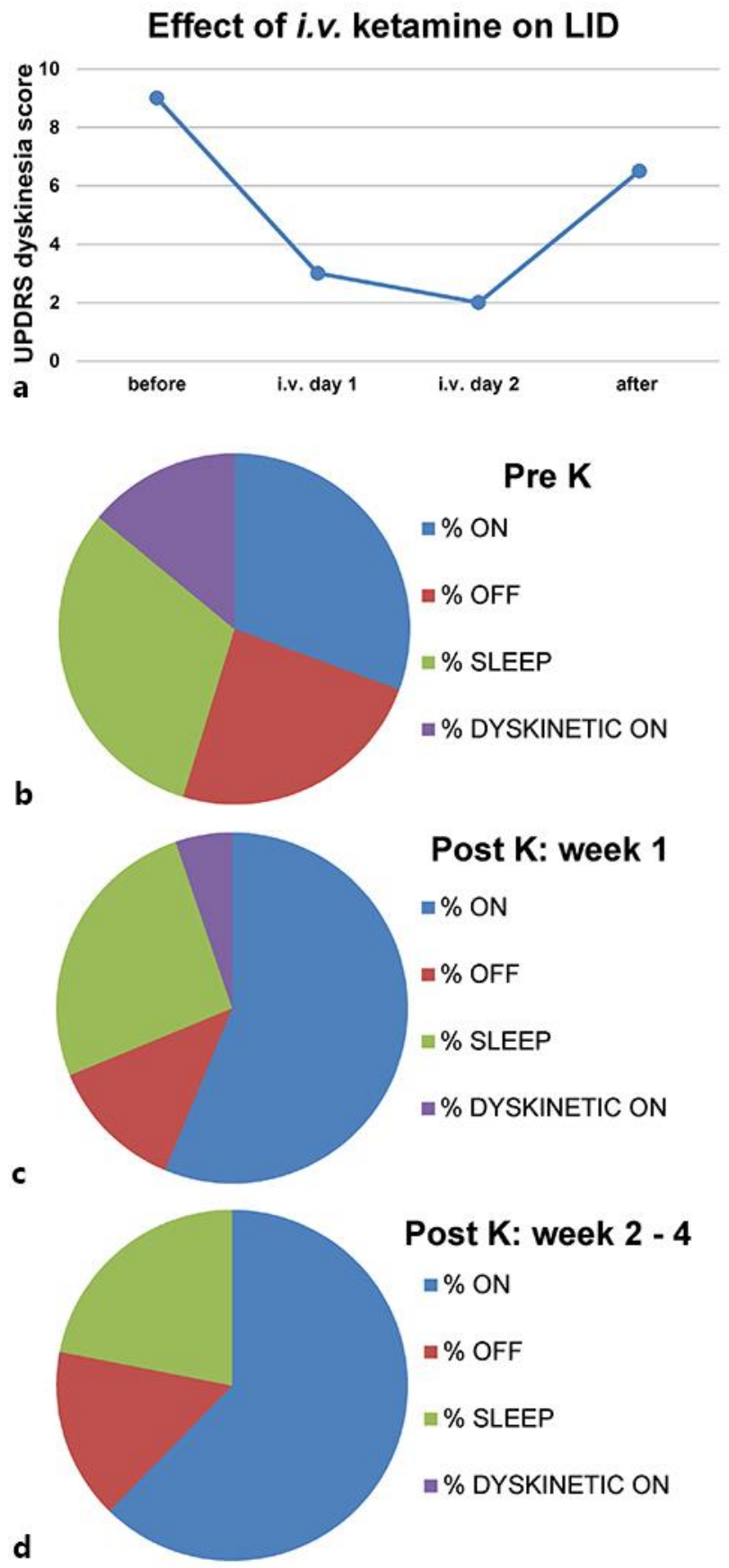

Fig. 1. UPDRS dyskinesia score and \% dyskinesia on time is reduced by low-dose ketamine infusion in case No. 1. The graph (a) shows the UPDRS dyskinesia score (sum of items 32-34) before, during and after the low-dose ketamine infusion (starting dose: $0.05 \mathrm{mg} / \mathrm{kg} / \mathrm{h}$; maximal dose: $0.3 \mathrm{mg} / \mathrm{kg} / \mathrm{h}$, for $50 \mathrm{~h}$ ). The charts in b-d show the \% time the patient spent in on, off, or dyskinetic on time, or was asleep during $24 \mathrm{~h}$, based on the patient diary. In $\mathbf{b}$, the average of 4 days pre-K is shown, and in $\mathbf{c}$, the average of the 1 st week post-K. In $\mathbf{d}$, the average of weeks $2-4$ post-K is depicted, and during this time, the LID had completely resolved. $\mathrm{K}=50$-hour low-dose intravenous ketamine infusion. 